\title{
Ocorrência de vírus em batata em sete estados do Brasil
}

\author{
Antônio Carlos de Ávila ${ }^{1 *}$; Paulo Eduardo de Melo ${ }^{1 *}$; Lindolfo R Leite ${ }^{2}$; Alice K Inoue-Nagata1 \\ ${ }^{1}$ Embrapa Hortaliças, C. Postal 218, 70359-970 Brasília-DF; ${ }^{2}$ Faculdades Integradas da Terra de Brasília, Ciências Biológicas, Q. 203, \\ Lote 32, Recanto das Emas, 72610-300, Brasília-DF; * Os dois primeiros autores contribuíram igualmente para este trabalho; avila@cnph. \\ embrapa.br; paulo@cnph.embrapa.br
}

\section{RESUMO}

As viroses causam rápida degenerescência dos tubérculossementes de batata. Em condições tropicais, em que a presença de afídeos vetores é constante e a estrutura das populações de vírus é dinâmica, a pressão das doenças é enorme. Conhecer essa dinâmica é uma ferramenta importante para a sustentabilidade da produção de batata. Realizou-se um levantamento abrangente da ocorrência de viroses em batata no Brasil, além de estudar-se a distribuição das estirpes de Potato virus Y (PVY) associadas ao mosaico da batata. Em 2005 e 2006 foram visitadas lavouras em sete estados brasileiros, coletando-se folíolos com sintomas de viroses (1.256 amostras) e amostras aleatórias (360 amostras). Foi feita também uma estimativa visual da incidência de mosaico e enrolamento-das-folhas em vários dos campos visitados. Das 1.256 amostras suspeitas, 840 apresentaram reação positiva em teste sorológico para PVY (66,9\%), 128 para Potato leaf roll virus (PLRV) (10,2\%), 79 para Potato virus $S$ (PVS) $(6,3 \%)$ e nenhuma para Potato virus $X$ (PVX). Os resultados dos testes de detecção por DAS-ELISA, biológico e RT-PCR mostraram a presença quase absoluta do subgrupo necrótico de PVY, em sua maioria PVYNTN . A análise de uma sub-amostragem em todos os municípios visitados confirmou que essa variante está hoje presente nos sete estados visitados. Amostras de PVY ${ }^{\mathrm{NTN}}$ foram obtidas das cultivares Asterix, Atlantic, Agata, Achat, Baronesa, Baraka, Bintje, Caesar, Cupido, Marijke, Monalisa, Panda e Vivaldi, que apresentaram diferentes níveis de suscetibilidade. As amostras aleatórias revelaram um quadro muito similar ao encontrado com as amostras sintomáticas. PLRV foi identificado em MG, BA, PR e SC, em várias lavouras de forma muito freqüente. PVS foi identificado nesses mesmos estados e também em SP. PVX foi detectado em apenas uma amostra tomada ao acaso em Serra do Salitre (MG). O contraste entre a avaliação visual dos sintomas e os resultados do teste de detecção por ELISA revelou a possibilidade de infecção latente por PVY em níveis relevantes na cultivar Asterix.

Palavras-chave: Solanum tuberosum subsp. tuberosum, RT-PCR (reverse transcriptase-polymerase chain reaction), DAS-ELISA (Double antibody sandwich- Enzyme linked Immunosorbent assay), PVY, PLRV, PVS.

\section{ABSTRACT}

\section{Virus occurrence in potatoes in seven Brazilian States}

Viruses are responsible for the quick degeneration of potato seedtubers. In the tropics, where aphid vectors are constantly present and the structure of virus populations is dynamic, the disease pressure is enormous. Therefore, the knowledge of such dynamics is definitely an extremely valuable tool towards the sustainability of the national potato production. In this study, we report a broad survey of virus occurrence in potato, in Brazil. In addition, we studied the distribution of the Potato virus Y (PVY) strains associated with mosaic symptoms on potatoes. In 2005 and 2006, we visited potato fields in seven Brazilian States. We collected leaves of symptomatic plants (1,256 samples) and also at random (360 samples). In addition, in several fields a visual assessment was carried out to estimate mosaic and leafroll incidence. From the 1,256 samples with symptoms, 840 tested serologically were positive to PVY (66.9\%), 128 to PLRV (10.2\%), 79 to PVS (6.3\%), and none to PVX. Serology using DAS-ELISA and also biological and RT-PCR tests revealed an almost exclusive occurrence of the PVY necrotic strain, predominantly the necrotic subgroup PVY ${ }^{\mathrm{NTN}}$. The analysis of a sub-sample representing all surveyed Counties indicated that the necrotic strain was universally present. Cultivars Asterix, Atlantic, Agata, Achat, Baronesa, Baraka, Bintje, Caesar, Cupido, Marijke, Monalisa, Panda, and Vivaldi, although displaying different susceptibility levels, were all infected by PVYNTN. The analysis of leaves collected at random showed similar results. PLRV was identified in four States (Minas Gerais, Bahia, Paraná, and Santa Catarina), while PVS was present in the State of São Paulo as well. PVX was found in only one sample collected at random in Serra do Salitre, State of Minas Gerais. The contrast between visual evaluation and the results of the detection test by ELISA strongly indicated the presence of a relevant rate of PVY latent infection on cultivar Asterix.

Keywords: Solanum tuberosum subsp. tuberosum, RT-PCR (reverse transcriptase-polymerase chain reaction), DAS-ELISA (Double antibody sandwich- Enzyme linked Immunosorbent assay), PVY, PLRV, PVS.

(Recebido para publicação em 9 de abril de 2009; aceito em 23 de novembro de 2009) (Received in April 9, 2009; accepted in November 23, 2009)

\begin{abstract}
$\mathrm{A}^{\mathrm{n}}$ produção mundial de batata em 2007 foi superior a 321 milhões de toneladas, colhida em quase 20 milhões de hectares (FAO, 2009). Esses valores não só colocam a batata como o quarto alimento em volume de produção em todo o mundo, atrás apenas do trigo, milho e arroz, como também mostram que a batateira é uma das plantas mais
\end{abstract}

eficientes na produção de energia por unidade de área e tempo.

Comparada aos grãos, a batatateira é também uma planta mais eficiente em termos nutricionais: uma lavoura de batata produz 54 e $78 \%$ mais proteína por unidade de tempo e área que lavouras de respectivamente trigo e arroz (Stevenson et al., 2001). No Brasil, a produção de batata em 2008 foi superior a 3,5 milhões de toneladas, em uma área de 144 mil hectares (IBGE, 2009), enquanto o valor movimentado pela cadeia brasileira da batata em 2006 foi de aproximadamente 1,9 bilhão de reais.

Em 2007, as regiões Sudeste e Sul foram responsáveis por praticamente 
$90 \%$ da batata produzida no Brasil, enquanto as áreas com altitude a partir de $900 \mathrm{~m}$ das regiões Centro-Oeste e Nordeste, especialmente o município de Cristalina em Goiás, e a Chapada Diamantina, na Bahia, responderam pelo restante da produção nacional (Legnaro \& Sábio, 2007). Essas áreas possuem condições climáticas excepcionais para o cultivo da batata e não raro a produtividade supera $40 \mathrm{t} \mathrm{ha}^{-1}, 60 \%$ acima da média brasileira, 25,4 t ha-1 em 2008 (IBGE, 2009).

Para fins comerciais a batatateira é propagada através de tubérculos. A propagação vegetativa do insumo "semente" torna a produção e utilização de tubérculos-sementes de alta qualidade um dos pontos críticos do sistema produtivo de batata. Quando o índice de adoção de tubérculos-sementes de alta qualidade cai, os impactos negativos sobre a sanidade e produtividade da lavoura são imediatos.

As viroses são um dos problemas fitossanitários que primeiro aparecem em virtude do abandono da prática de utilização de tubérculos-sementes de alta qualidade. As perdas na produção causadas por vírus em batata são muito variáveis em função das diferentes condições de crescimento das plantas e os métodos de análise utilizados.

São duas as viroses que causam maior impacto econômico em batata no Brasil: o enrolamento-das-folhas e o mosaico. A primeira é causada por um luteovírus (Potato leaf roll virus) transmitido por pulgões, cujos sintomas se manifestam em especial nas folhas mais velhas, que se tornam enrijecidas e terminam por se enrolar para cima (Salazar, 1996).

As perdas em produtividade em função do enrolamento-das-folhas podem chegar a 50\% (Câmara et al, 1986; Filgueira \& Câmara, 1986). Os mosaicos podem aparecer em função da infecção das plantas de batata por diferentes vírus, sendo o Potato virus $Y$ (PVY) o mais importante deles.

O PVY também é transmitido por pulgões. Três estirpes são reconhecidas para PVY: $\mathrm{PVY}^{\mathrm{O}}, \mathrm{PVY}^{\mathrm{N}}$ e $\mathrm{PVY}^{\mathrm{C}}$, sendo que as duas primeiras já foram relatadas no Brasil, assim como a variante
PVY ${ }^{\text {NTN }}$ (Salazar, 1996; Singh et al., 2008), que causa mosaico com pontuações cloróticas e deformação nas folhas, além de induzirem sintomas de necrose na forma de anéis, números e letras nos tubérculos (Fonseca et al, 2005). As perdas causadas por PVY podem variar de 30 a 100\%, dependendo da cultivar (Kus, 1995).

O cultivo de batata no Brasil, devido às condições tropicais e sub-tropicais predominantes nas regiões produtoras, sofre grande pressão de viroses.

Os afídeos vetores estão presentes durante todo o ano, com picos de população nas épocas mais secas. Além dos afídeos, há ocorrência natural de inúmeras solanáceas silvestres (Fontes \& Melo, 1999) e de soqueiras de lavouras de batata que servem como repositório de vírus. Essa constante presença de vetores e fontes de vírus é especialmente crítica para o manejo dos danos causados por PVY, já que constituem quesitos básicos para a recombinação do vírus e surgimento de novas estirpes. Com isso, cultivares que vinham se comportando como resistentes até então, podem passar a apresentar reação de suscetibilidade e novos sintomas podem aparecer. Por isso, conhecer a dinâmica das viroses que incidem sobre a batata no Brasil é uma ferramenta de enorme valia para manter a doença em níveis que permitam uma produção adequada de tubérculos-sementes e, consequentemente, auxiliem na sustentabilidade do agronegócio da batata.

Neste trabalho realizou-se um levantamento abrangente da ocorrência de viroses em lavouras de batata no Brasil e, a partir das amostras coletadas com PVY, caracterizou-se a disseminação das estirpes desse vírus associadas ao mosaico da batata.

\section{MATERIAL E MÉTODOS}

Foram analisadas amostras provenientes de sete estados brasileiros. As primeiras amostras, em número limitado, foram recebidas do Espírito Santo, em agosto de 2005. A partir de então, todas as amostras foram coletadas em lavouras comerciais. Neste mesmo mês, foram obtidas amostras no município de
Cristalina, em Goiás. Em novembro do mesmo ano, foram coletadas amostras nos municípios de Vargem Grande do Sul e Itapetininga, em São Paulo, e Senador Amaral e Bom Repouso, no sul de Minas Gerais.

Em março de 2006, foram amostrados os municípios de Ibicoara, distritos de Cascavel e Guaíra, e Mucugê, na Chapada Diamantina, na Bahia. No mês seguinte, foram obtidas amostras nos municípios de Araxá, distrito de Perdizes, e Serra do Salitre, na região do Alto Paranaíba, em Minas Gerais. As últimas amostras foram coletadas em outubro de 2006, no Paraná e Santa Catarina, sendo as únicas geo-referenciadas neste levantamento.

As amostras paranaenses foram provenientes de Araucária, distrito de Fazendinha; Contenda, distrito de Lagoa das Almas e; Lapa, municípios da região metropolitana de Curitiba; além de Castro, Castrolanda e Teixeira Soares, distritos de Rio d'Areia e Rio das Almas, região dos Campos Gerais. As amostras catarinenses foram provenientes do Planalto Norte-Catarinense, município de Canoinhas, distritos de Laranjeira e Rio do Pinho, e dos municípios de Irineópolis, Mafra e Papanduva.

Em cada município ou distrito foram coletadas de 11 a 148 amostras de folíolos de batatateira (Tabela 1). Foram coletadas amostras com sintomas de viroses para a identificação de espécies/ estirpes de PLRV, Potato virus X(PVX), PVY e Potato virus S(PVS) a posteriori no laboratório de virologia da Embrapa Hortaliças.

Além das amostras com sintomas visuais, em Serra do Salitre (MG); nos distritos de Rio das Almas e Rio d'Areia, em Teixeira Soares (PR); em Irineópolis ( $\mathrm{SC}$ ); distrito de Rio do Pinho, em Canoinhas (SC) e; Mafra (SC), foram coletadas também 20 amostras ao acaso (Tabela 1) em cada campo, com o objetivo de estimar a incidência de vírus nessas lavouras. Para coleta das amostras aleatórias, caminhou-se no campo em zigue-zague, contando-se as plantas e coletando-se folhas a cada décima planta.

No total, foram coletadas 1.256 amostras com sintomas de virose e 360 amostras aleatórias de folíolos de 
Tabela 1. Incidência de vírus detectados por DAS-ELISA em amostras de folíolos de batateira com sintomas visuais, provenientes de lavouras comerciais (incidence of viruses detected via DAS-ELISA in potato leaflet samples with visual symptoms, collected in commercial fields). Brasília, Embrapa Hortaliças, 2009.

\begin{tabular}{|c|c|c|c|c|c|c|c|c|}
\hline \multirow{2}{*}{ Estado } & \multirow{2}{*}{$\begin{array}{l}\text { Data da coleta } \\
\text { (mês/ano) }\end{array}$} & \multirow{2}{*}{ Município (distrito) } & \multirow{2}{*}{ Cultivar } & \multirow{2}{*}{$\begin{array}{c}\text { No.de } \\
\text { amostras }\end{array}$} & \multicolumn{4}{|c|}{ Incidência de viroses (\%) } \\
\hline & & & & & $\mathbf{P V Y}^{4}$ & $\mathrm{PVS}^{4}$ & PLRV $^{4}$ & $\mathbf{P V X}^{4}$ \\
\hline ES & $08 / 2005$ & Não indicado ${ }^{1}$ & Não indicado ${ }^{1}$ & 13 & 69,2 & 0,0 & 0,0 & 0,0 \\
\hline $\mathrm{GO}$ & $08 / 2005$ & Cristalina & Ágata & 36 & 36,1 & 0,0 & 0,0 & 0,0 \\
\hline \multirow{2}{*}{ SP } & \multirow{2}{*}{$09 / 2005$} & Itapetininga & Atlantic & 30 & 93,3 & 16,7 & 0,0 & 0,0 \\
\hline & & Vargem Grande do Sul & Achat & 11 & 90,1 & 18,2 & 0,0 & 0,0 \\
\hline \multirow{13}{*}{ MG } & \multirow{6}{*}{$11 / 2005$} & \multirow{4}{*}{ Bom Repouso } & Ágata & 8 & 100,0 & 12,5 & 62,5 & 0,0 \\
\hline & & & Asterix & 12 & 91,7 & 16,7 & 8,3 & 0,0 \\
\hline & & & Baraka & 4 & 100,0 & 0,0 & 0,0 & 0,0 \\
\hline & & & Monalisa & 7 & 85,7 & 0,0 & 0,0 & 0,0 \\
\hline & & \multirow{2}{*}{ Senador Amaral } & Asterix & 6 & 100,0 & 0,0 & 0,0 & 0,0 \\
\hline & & & Baraka & 9 & 100,0 & 0,0 & 0,0 & 0,0 \\
\hline & \multirow{7}{*}{$04 / 2006$} & \multirow{4}{*}{ Araxá (Perdizinha) } & Ágata G32 & 30 & 80,0 & 0,0 & 40,0 & 0,0 \\
\hline & & & Cupido G32 & 39 & 30,8 & 0,0 & 2,6 & 0,0 \\
\hline & & & FL $2055 \mathrm{G} 2^{2}$ & 28 & 96,4 & 0,0 & 7,1 & 0,0 \\
\hline & & & Vivaldi $\mathrm{G} 2^{2}$ & 22 & 72,7 & 0,0 & 27,3 & 0,0 \\
\hline & & \multirow{3}{*}{ Serra do Salitre } & Asterix & 35 & 94,3 & 0,0 & 2,6 & 0,0 \\
\hline & & & Atlantic & 23 & 100,0 & 0,0 & 4,3 & 0,0 \\
\hline & & & Marijke & 23 & 100,0 & 0,0 & 0,0 & 0,0 \\
\hline \multirow{6}{*}{ BA } & \multirow{6}{*}{$04 / 2006$} & Ibicoara (Cascavel) & Ágata & 7 & 28,6 & 42,9 & 42,9 & 0,0 \\
\hline & & Ibicoara (Guaíra) & Vivaldi & 4 & 0,0 & 0,0 & 0,0 & 0,0 \\
\hline & & \multirow{4}{*}{ Mucugê } & $\overline{\text { Ágata } \mathrm{G} 1^{2}}$ & 6 & 100,0 & 0,0 & 16,7 & 0,0 \\
\hline & & & Ágata $^{3}$ & 20 & 95,0 & 30,0 & 0,0 & 0,0 \\
\hline & & & Vivaldi G32 & 4 & 25,0 & 50,0 & 0,0 & 0,0 \\
\hline & & & Vivaldi & 7 & 28,6 & 0,0 & 28,6 & 0,0 \\
\hline \multirow{12}{*}{ PR } & \multirow{12}{*}{$10 / 2006$} & Castro & Atlantic G42 & 33 & 54,5 & 6,1 & 0,0 & 0,0 \\
\hline & & Castrolanda & Atlantic $\mathrm{G1}^{2}$ & 50 & 54,0 & 26,0 & 0,0 & 0,0 \\
\hline & & & Asterix G32 & 52 & 100,0 & 26,9 & 13,5 & 0,0 \\
\hline & & Contenda (Lagoa das Almas) & Monalisa & 41 & 92,7 & 0,0 & 2,4 & 0,0 \\
\hline & & & Panda G6 ${ }^{2}$ & 37 & 100,0 & 43,2 & 45,9 & 0,0 \\
\hline & & Araucária (Fazendinha) & Asterix & 66 & 86,4 & 40,9 & 3,0 & 0,0 \\
\hline & & I ana & Ágata & 38 & 94,7 & 5,3 & 0,0 & 0,0 \\
\hline & & Lapa & Asterix & 14 & 92,9 & 0,0 & 0,0 & 0,0 \\
\hline & & Texeira Soares (Rio d'Areia) & Caesar G2 $^{2}$ & 34 & 23,5 & 0,0 & 0,0 & 0,0 \\
\hline & & & Ágata $\mathrm{G} 2^{2}$ & 33 & 87,9 & 12,1 & 3,0 & 0,0 \\
\hline & & Iexeira soares (Kio das & Atlantic $\mathrm{G} 2^{2}$ & 36 & 100,0 & 0,0 & 8,3 & 0,0 \\
\hline & & & Monalisa & 38 & 78,9 & 31,6 & 7,9 & 0,0 \\
\hline & & & Ágata & 32 & 96,9 & 9,4 & 9,4 & 0,0 \\
\hline & & Canoinhas (Laranjeira) & Monalisa & 47 & 95,7 & 4,3 & 2,1 & 0,0 \\
\hline & & & Agata G3 $^{2}$ & 26 & 0,0 & 7,7 & 3,8 & 0,0 \\
\hline & & Canoinhas (Rio do Pinho) & Baronesa G32 & 36 & 41,7 & 5,6 & 0,0 & 0,0 \\
\hline & & & Monalisa G2² & 19 & 26,3 & 0,0 & 0,0 & 0,0 \\
\hline $\mathrm{SC}$ & $10 / 2006$ & & Asterix & 13 & 0,0 & 0,0 & 0,0 & 0,0 \\
\hline & & Irineónolis & Baraka G12 & 14 & 0,0 & 0,0 & 0,0 & 0,0 \\
\hline & & Irmeopons & Cupido G32 & 36 & 2,8 & 0,0 & 2,8 & 0,0 \\
\hline & & & Vivaldi $\mathrm{G} 1^{2}$ & 21 & 0,0 & 4,8 & 0,0 & 0,0 \\
\hline & & & Asterix $\mathrm{G} 2^{2}$ & 28 & 89,3 & 21,4 & 0,0 & 0,0 \\
\hline & & Matra & Bintje G12 & 11 & 72,7 & 0,0 & 9,1 & 0,0 \\
\hline & & Papanduva & Asterix & 50 & 66,0 & 2,0 & 4,0 & 0,0 \\
\hline Total & & & & 1.256 & & & & \\
\hline
\end{tabular}

${ }^{1}$ Quando recebidas, as amostras provenientes do ES não indicavam o município de coleta e a cultivar de batata (samples from Espirito Santo State had neither city, nor cultivar identification upon arrival); ${ }^{2} \mathrm{Gn}=$ número de gerações ou multiplicações em campo (number of field generations or multiplications); ${ }^{3}$ Semente básica (foundation seed); ${ }^{4} \mathrm{PVY}=$ Potato virus $Y$; PVS= Potato virus $S ; \mathrm{PLRV}=$ Potato leaf roll virus; $\mathrm{PVX}=$ Potato virus $X$ 
batatateira. Foi feita ainda uma estimativa visual da incidência de mosaico e enrolamento-das-folhas em cada campo visitado. A estimativa foi feita contandose o número de plantas com sintomas visuais de mosaico e enrolamento-dasfolhas em cada campo, em no mínimo dez lotes de dez plantas tomadas ao acaso.

Foram coletadas amostras das cultivares Achat, Agata, Asterix, Atlantic, Baraka, Baronesa, Bintje, Caesar, Cupido, Marijke, Monalisa, Panda e Vivaldi (Tabela 1), em lavouras destinadas tanto à produção de tubérculos para consumo, quanto para semente. As espécies de vírus foram identificadas através de DAS-ELISA (Clark \& Adams, 1977) com anti-soros policlonais para PVY, PLRV, PVX e PVS.

Para diferenciação fenotípica das estirpes de PVY, 1.153 amostras com sintomas visuais foram inoculadas mecanicamente em plantas de Nicotiana tabacum, cultivares Samsun e TNN, e armazenadas a $-80^{\circ} \mathrm{C}$.

Para identificar uma possível infecção mista com outros vírus, os isolados foram adicionalmente inoculados em plantas de Datura stramonium. Todas as inoculações foram feitas utilizando tampão trisfosfato monobásico $0,01 \mathrm{M}$, pH 7,0, adicionado de $0,1 \% \mathrm{Na}_{2} \mathrm{SO}_{3}$, utilizando Carborundum 600 mesh como abrasivo.

Para a diferenciação das estirpes e subgrupos necróticos de PVY (PVYO, PVY $^{\mathrm{N}}$ e PVYNTN) foi utilizado o método de Weilguny \& Singh (1998), com modificações (Fonseca et al., 2005). Para cada município ou distrito foram tomadas cinco amostras ao acaso para RT-PCR (Fonseca et al., 2005).

\section{RESULTADOS E DISCUSSÃO}

\section{Ocorrência de viroses em lavouras}

\section{de batata - Das 1.256 amostras com} suspeita de sintomas de virose analisadas (Tabela 1), 840 apresentaram reação positiva para PVY $(66,9 \%), 128$ para PLRV (10,2\%), 79 para PVS (6,3\%) e nenhuma para PVX. PVY foi o único vírus identificado em todos os estados. PLRV foi identificado em MG, BA, PR e SC, em várias lavouras de forma muito frequente. PVS, no passado com detecção esporádica, foi identificado nesses mesmos estados e também em SP. Este resultado indica que, atualmente, PVY é o principal vírus da batateira no Brasil.

A prevalência do PVY representa uma completa reversão no quadro de viroses do país. Nas últimas três décadas, PLRV era considerado o vírus predominante e a principal causa da degenerescência da batata no Brasil (Daniels, 1995; Figueira, 1995; SouzaDias, 1995).

Os resultados das amostras aleatórias (Tabela 2) confirmaram o quadro obtido a partir das amostras suspeitas (Tabela 1): a presença generalizada de PVY e a ocorrência freqüente de PLRV e PVS (Tabela 2).

PVY apareceu como o vírus de maior relevância, com até $100 \%$ de incidência, enquanto PLRV e PVS atingiram incidência máxima de $25 \%$. No caso específico de PLRV, não foi observada incidência importante em áreas onde PVY também não tenha sido identificado em níveis muito elevados. Esta associação entre a incidência das duas viroses decorre do desordenamento e informalização do sistema de produção de tubérculos-sementes no Brasil (Figueira, 2006; Ávila et al., 2007).

No caso das amostras aleatórias, identificou-se ainda uma amostra proveniente de Serra do Salitre com reação positiva para PVX.

$\mathrm{O}$ estudo detalhado das amostras aleatórias mostrou que as grandes variações na incidência de viroses estão relacionadas à localização e ao manejo da lavoura. Onde são aplicados os requisitos recomendados para a produção de tubérculos-sementes como, por exemplo, isolamento das lavouras, plantio de tubérculos-sementes de alta qualidade e erradicação de plantas com sintomas, a incidência de viroses foi muito baixa. É o caso das lavouras visitadas em Serra do Salitre, quando destinadas à produção de sementes, Ireneópolis e Canoinhas, distrito de Rio do Pinho, em Santa Catarina, região tradicional de produção de tubérculos-sementes, e Castro (Tabela 2).

Em Castro, a preocupação é tão grande com a sanidade, que em uma das lavouras visitadas, a cultivar Atlantic, que é suscetível a PVY (Daniels \& Pereira, 2004; Crosslin et al., 2006), apesar de estar já na quarta geração de campo, apresentava apenas $10 \%$ de incidência do vírus (Tabela 2).

Em Mafra, foi possível observar o quanto o isolamento da lavoura influi na qualidade da semente. Em uma lavoura mantida com isolamento, cercada por áreas de reflorestamento, a cultivar Bintje apresentou incidência de 5,3\% tanto de PVY, quanto de PLRV. Em outra lavoura, em área aberta, a cultivar Asterix apresentou 30,0 e 5,0\% de PVY e PLRV, respectivamente.

Cabe ressaltar que os tubérculos utilizados para instalação de ambas as lavouras estavam na mesma geração de campo e que, ainda que a incidência de viroses na cultivar Bintje tenha sido muito mais baixa, ambas as cultivares têm nível de suscetibilidade similar (NIVAP, 2007).

Todavia, somente o isolamento da área não é suficiente para garantir a produção de tubérculos-sementes de alta qualidade. A região da Chapada Diamantina, na Bahia, é um bom exemplo. Embora seja relativamente nova para a produção de batata no Brasil e até certo ponto isolada de outras regiões produtoras, a Chapada Diamantina já apresenta níveis muito altos de incidência de viroses (Tabela 1).

Uma das causas mais prováveis para a disseminação de vírus na região é a introdução de tubérculos-sementes infectados. No presente levantamento os resultados de sorologia confirmaram que as plantas com sintomas visuais amostradas em campos instalados em Mucugê com tubérculos-sementes básicos adquiridos de outra região brasileira, estavam verdadeiramente infectadas (Tabela 1).

A região de Contenda, onde é prática comum utilizar como semente tubérculos que deveriam ser destinados ao consumo, apresentou a incidência mais alta de vírus entre todas as regiões amostradas (Tabela 2).

Para agravar a situação, é costume dos produtores locais multiplicarem por várias gerações o tubérculo-semente assim adquirido, mantendo para o 
Tabela 2. Incidência de vírus detectados por DAS-ELISA em amostras de folíolos de batatateira coletados aleatoriamente em lavouras comerciais e estimativa visual da incidência de viroses (incidence of viruses detected via DAS-ELISA in potatp leaflet samples collected at random in commercial fields and visual estimate of viruses incidente). Brasília, Embrapa Hortaliças, 2009.

\begin{tabular}{|c|c|c|c|c|c|c|c|c|}
\hline \multirow[b]{2}{*}{ Estado } & \multirow[b]{2}{*}{$\begin{array}{l}\text { Município } \\
\text { (distrito) }\end{array}$} & \multirow[b]{2}{*}{ Cultivar } & \multirow[b]{2}{*}{$\begin{array}{l}\text { PVY } \\
(\%)\end{array}$} & \multirow[b]{2}{*}{$\begin{array}{l}\text { PVS } \\
(\%)\end{array}$} & \multirow[b]{2}{*}{$\begin{array}{l}\text { PLRV } \\
(\%)\end{array}$} & \multirow[b]{2}{*}{$\begin{array}{l}\text { PVX } \\
(\%)\end{array}$} & \multicolumn{2}{|c|}{ Avaliação visual } \\
\hline & & & & & & & $\begin{array}{c}\text { Mosaico } \\
(\%)\end{array}$ & $\begin{array}{c}\text { Enrolamento } \\
(\%)\end{array}$ \\
\hline \multirow{2}{*}{ MG } & \multirow{2}{*}{ Serra do Salitre } & Atlantic & 8,3 & 0,0 & 0,0 & 0,0 & $\mathrm{nr}^{1}$ & $\mathrm{nr}$ \\
\hline & & Asterix & 0,0 & 0,0 & 0,0 & 2,4 & $\mathrm{nr}$ & $\mathrm{nr}$ \\
\hline \multirow{13}{*}{ PR } & \multirow{2}{*}{ Araucária (Fazendinha) } & Asterix & 73,7 & 0,0 & 0,0 & 0,0 & 21,0 & 2,0 \\
\hline & & Asterix & 100,0 & 5,0 & 10,0 & 0,0 & 43,0 & 16,0 \\
\hline & Castro & Atlantic G42 & 10,0 & 0,0 & 0,0 & 0,0 & 7,0 & 0,0 \\
\hline & Castrolanda & Atlantic G1 ${ }^{2}$ & 5,0 & 0,0 & 5,0 & 0,0 & 8,0 & 0,0 \\
\hline & \multirow{3}{*}{$\begin{array}{l}\text { Contenda (Lagoa das } \\
\text { Almas) }\end{array}$} & Asterix G32 & 100,0 & 5,0 & 5,0 & 0,0 & 28,0 & 0,0 \\
\hline & & Panda G6 $6^{2}$ & 100,0 & 0,0 & 25,0 & 0,0 & 100,0 & 20,0 \\
\hline & & Monalisa & 55,5 & 0,0 & 22,2 & 0,0 & 41,0 & 31,0 \\
\hline & \multirow{3}{*}{ Lapa } & Ágata & 78,9 & 0,0 & 0,0 & 0,0 & 81,0 & 11,0 \\
\hline & & Monalisa & 65,0 & 0,0 & 20,0 & 0,0 & 70,0 & 10,0 \\
\hline & & Asterix & 80,0 & 25,0 & 15,0 & 0,0 & 91,0 & 10,0 \\
\hline & $\begin{array}{l}\text { Teixeira Soares (Rio } \\
\text { d'Areia) }\end{array}$ & Caesar G2² & 10,5 & 0,0 & 5,3 & 0,0 & 5,0 & 0,0 \\
\hline & \multirow{2}{*}{$\begin{array}{l}\text { Teixeira Soares (Rio } \\
\text { das Almas) }\end{array}$} & Ágata $\mathrm{G} 2^{2}$ & 5,0 & 15,0 & 5,0 & 0,0 & 10,0 & 2,0 \\
\hline & & Atlantic $\mathrm{G} 2^{2}$ & 55,0 & 0,0 & 5,0 & 0,0 & 47,0 & 0,0 \\
\hline \multirow{11}{*}{$\mathrm{SC}$} & Canoinhas (Laranjeiras) & Ágata & 30,0 & 0,0 & 15,0 & 0,0 & 34,0 & 34,0 \\
\hline & \multirow{3}{*}{$\begin{array}{l}\text { Canoinhas (Rio do } \\
\text { Pinho) }\end{array}$} & Ágata $\mathrm{G}^{2}$ & 0,0 & 0,0 & 0,0 & 0,0 & 0,0 & 0,0 \\
\hline & & Baronesa $\mathrm{G} 3^{2}$ & 0,0 & 0,0 & 10,0 & 0,0 & 4,0 & 10,0 \\
\hline & & Monalisa $\mathrm{G} 2^{2}$ & 0,0 & 0,0 & 0,0 & 0,0 & 0,0 & 4,0 \\
\hline & \multirow{3}{*}{ Irineópolis } & Baraka G12 & 0,0 & 0,0 & 0,0 & 0,0 & 0,0 & 0,0 \\
\hline & & Baraka $^{3}$ & 0,0 & 0,0 & 0,0 & 0,0 & 0,0 & 0,0 \\
\hline & & Vivaldi $^{4}$ & 0,0 & 0,0 & 20,0 & 0,0 & 1,0 & 10,0 \\
\hline & \multirow{2}{*}{ Mafra } & Bintje $G 2^{2}$ & 5,3 & 0,0 & 5,3 & 0,0 & 5,0 & 0,0 \\
\hline & & Asterix $\mathrm{G} 2^{2}$ & 30,0 & 0,0 & 5,0 & 0,0 & 14,0 & 1,0 \\
\hline & \multirow{2}{*}{ Papanduva } & Asterix & 10,5 & 5,3 & 5,3 & 0,0 & 10,0 & 2,0 \\
\hline & & Monalisa & 85,0 & 0,0 & 5,0 & 0,0 & 79,0 & 75,0 \\
\hline Total & & & 52,8 & 3,1 & 10,6 & & & \\
\hline
\end{tabular}

${ }^{1} \mathrm{nr}=$ não realizada (not done); ${ }^{2} \mathrm{Gn}=$ número de gerações ou multiplicações em campo (number of field generations or multiplications); ${ }^{3}$ Minitubérculos (minitubers); ${ }^{4}$ Semente-básica importada (imported foundation seed).

próximo plantio os tubérculos menores, justamente aqueles que têm maior probabilidade de estarem infectados. Como conseqüência, os campos da região atingem rapidamente $100 \%$ de infecção.

Avaliações visuais $x$ sorologia - A comparação entre as avaliações visuais e sorológicas, particularmente para o PLRV e, em especial, em lavouras com baixa sanidade, foi discrepante. Nesses casos, a interferência de outros fatores, como sintomas de outros vírus e a ocorrência de rizoctoniose, prejudica a precisão da avaliação visual dos sinto- mas de enrolamento.

Em Canoinhas, distrito de Laranjeiras, e em Papanduva observou-se alta incidência de plantas com enrolamento apical em lavouras das cultivares Agata e Monalisa, respectivamente, sugerindo enrolamento primário (Tabela 2).

O sintoma apareceu quase sempre em associação com o mosaico. Entretanto, os resultados sorológicos indicaram que a incidência de PLRV era muito menor que aquela estimada visualmente. Sabe-se hoje que não se trata de enrolamento, mas de uma reação varietal de batata a uma variante do subgrupo necrótico de PVYNTN (Silva, 2008).

Observou-se discrepância entre leitura visual e sorologia na avaliação da incidência de mosaico para a cultivar Asterix, com os valores de incidência baseados em sintomas visuais mais baixos que os resultados obtidos em ELISA (Tabela 2).

Como para as demais cultivares os resultados da incidência visual de mosaico e a ocorrência de PVY são muito similares, a diferença observada na cultivar Asterix aponta para a possibilidade não só de haver infecção latente, mas de que aconteça em nível muito eleva- 
do. Por isso, para a cultivar Asterix, as medidas preventivas preconizadas para produção de tubérculos-sementes devem ser observadas ainda com maior rigor, aconselhando-se ainda o monitoramento sorológico do PVY.

Os subgrupos necróticos de PVY A inoculação mecânica em Nicotiana tabacum dos isolados coletados neste levantamento revelou a presença generalizada das estirpes necróticas de PVY. Das 1.153 amostras inoculadas, 405 não induziram sintomas, 745 estavam infectadas com $\mathrm{PVY}^{\mathrm{N}}$ e apenas três com $\mathrm{PVY}^{\mathrm{O}}$. Plantas de fumo infectadas com $\mathrm{PVY}^{\mathrm{O}}$ apresentam manchas em formato de pérola no limbo foliar. Já plantas infectadas com a estirpe PVYN e o subgrupo necrótico $\mathrm{PVY}{ }^{\mathrm{NTN}}$ não podem ser diferenciadas por sintomatologia, já que em ambos os casos, as plantas de fumo apresentam necrose de nervuras.

Também em batata, a distinção de variantes de PVY com base nos sintomas é bastante difícil. Os sintomas em geral são mosaico de leve a severo, manchas cloróticas, rugosidade e deformação das folhas.

A ocorrência dos subgrupos necróticos de PVY em batata não é um problema somente no Brasil (Ávila et al., 2007). A primeira descrição da ocorrência desses subgrupos foi feita há mais de duas décadas, na Hungria (Beczner et al., 1984). Posteriormente sua ocorrência foi relatada em vários outros países da Europa (Alemanha, Áustria, Bélgica, Dinamarca, França, Holanda, Polônia) (Beczner et al., 1984; Kerlan \& Le Romancer, 1992; Kus; 1995; Steinbach \& Hamann, 1989; van den Heuvel et al., 1994), no Líbano (Le Romancer et al., 1994), na América do Norte (Piche et al., 2004; Nie et al., 2004) e Japão (Oshima et al., 2000).

A diferenciação entre os subgrupos de PVYN neste estudo, via RT-PCR (Weilguny \& Singh, 1998; Fonseca et al., 2005), demonstrou que a maioria dos isolados encontrados nas amostras coletadas pertencem ao subgrupo necrótico PVY ${ }^{\mathrm{NTN}}$ (Figura 1), detectado no Espírito Santo, Goiás (Cristalina), São Paulo (Vargem Grande do Sul e Itapetininga), Minas Gerais (Bom Repouso, Senador Amaral, Serra do Salitre e Araxá, distrito de Perdizes),
Bahia (Mucugê e Ibicoara, Distrito de Cascavel), Paraná (Araucária, Distrito Fazendinha, Castro, Castrolanda e Contenda) e Santa Catarina (Canoinhas, Irineópolis, Mafra e Papanduva). PVY ${ }^{\text {NTN }}$ pode induzir sintomas nos tubérculos de batata (Souza-Dias, 2001) na forma de anéis, letras e números, embora nem sempre exista uma associação direta, pois os tubérculos infectados podem permanecer assintomáticos (Singh et al., 2008). Sabe-se que o armazenamento de tubérculo-semente em câmara fria é um fator que aumenta a incidência dos sintomas em tubérculos (Fonseca, 2003). À parte disso, são comuns diferentes estirpes e subgrupos do PVY infectarem a mesma planta.

Neste trabalho foi confirmada a presença de PVYNTN nas cultivares Achat, Agata, Asterix, Atlantic, Baraka, Baronesa, Bintje, Caesar, Cupido, Marijke, Monalisa, Panda e Vivaldi. Isso não indica que cultivares que não estejam nesta lista, não sejam também suscetíveis ao PVYNTN. Além de resistência e suscetibilidade, as cultivares de batata apresentam reações fenotípicas específicas a estirpes de PVY. Vários isolados presentes nas amostras coletadas neste estudo foram utilizados em inoculações controladas em diversas cultivares de batata na Embrapa Hortaliças (Silva, 2008). Na análise dos sintomas, foram evidentes as diferenças existentes entre dois isolados necróticos de PVY ${ }^{\mathrm{NTN}}$ : enquanto um deles induziu sintoma típico de encrespamento apical (Souza-Dias, 2006) nas cultivares Mondial, Monalisa e Canoinhas, o outro induziu apenas mosaico com manchas cloróticas.

No Brasil, o primeiro alerta fitossanitário da presença de PVYNTN foi feito em tubérculo-semente importado por Souza-Dias, em 1996. Desde então, observou-se uma rápida expansão de mosaicos em campos de batata nas principais regiões produtoras.

Estudos recentes também evidenciam a rápida disseminação desses subgrupos necróticos em vários países e mostram que se trata de recombinantes entre $\mathrm{PVY}^{\mathrm{O}}$ e $\mathrm{PVY} \mathrm{N}^{\mathrm{N}}$, gerando variantes do tipo PVY ${ }^{\mathrm{N}: \mathrm{O}}$ e PVY ${ }^{\mathrm{NTN}}$ (Piche et al., 2004; Nie et al., 2004; Singh et al., 2008).

Os estudos moleculares sobre PVY em batata no Brasil ainda são muito incipientes e não permitem conclusões seguras sobre a origem das estirpes presentes (Inoue-Nagata et al., 2001). Entretanto, o mais provável é que estejam

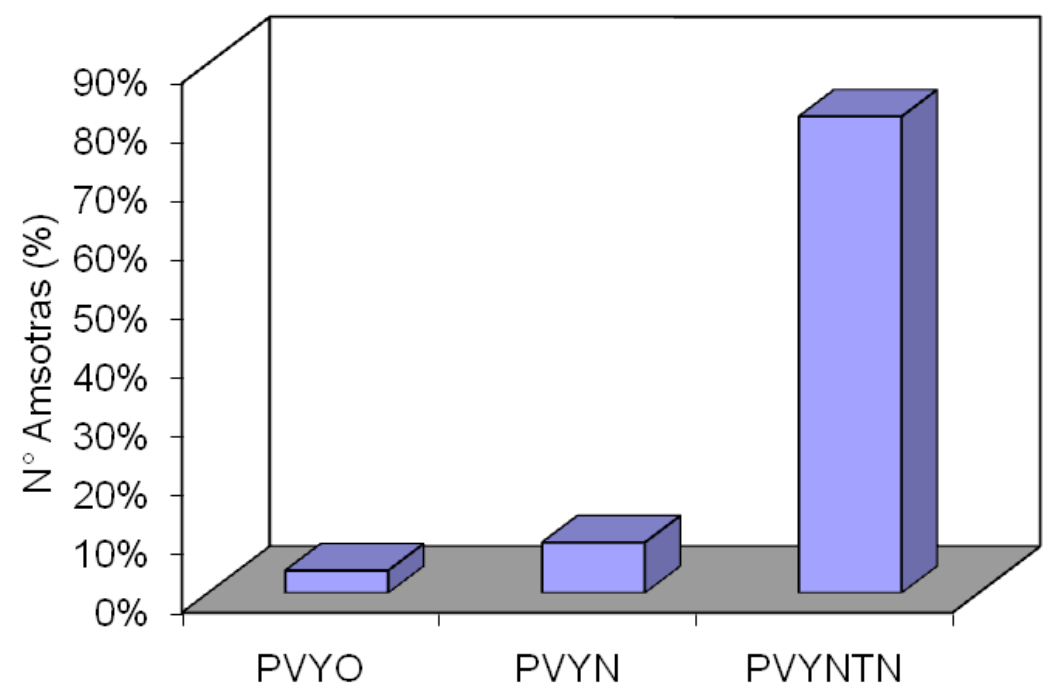

Figura 1. Incidência das estirpes e subgrupos necróticos do Potato virus $Y$ nos Estados de Espírito Santo, Goiás, Minas Gerais, Bahia, Paraná e Santa Catarina (incidence of necrotic Potato virus $Y$ strains and subgroups in the States of Espírito Santo, Goiás, Minas Gerais, Bahia, Paraná e Santa Catarina). Brasília, Embrapa Hortaliças, 2009. 
associadas a introduções eventuais no país via tubérculo-semente importado e também a recombinações espontâneas em nossos campos.

Este levantamento mostra um fato incontestável: a presença da estirpe necrótica de PVY em batata no Brasil é generalizada. Mais relevante ainda, a análise molecular das subamostras por localidade indicou a presença maciça do subgrupo necrótico PVYNTN (Figura 1), um forte indicativo de que hoje, no Brasil, as variantes necróticas do subgrupo PVY ${ }^{\mathrm{NTN}}$ predominam.

Várias devem ser as razões para esta ampla disseminação do subgrupo necrótico de PVY no país. Com relação ao vírus, a virulência dos isolados associada à alta concentração viral em muito favorece o surgimento de novos recombinantes (Nie et al., 2004). Adicionalmente, os sintomas causados pela estirpe necrótica na batatateira são mais brandos que aqueles causados por $\mathrm{PVY}^{\mathrm{O}}$ e podem passar despercebidos a campo.

Do ponto de vista da legislação, houve um descompasso entre a flexibilização do sistema de produção de tubérculo-semente e o credenciamento das "Unidades Certificadoras" previstas na lei (Figueira, 2006). Na ausência dessas, os produtores passaram a realizar autocertificação, resultando em uma enorme informalização do sistema de produção de sementes (Andreatta, 2006), com graves conseqüências fitossanitárias sobre a qualidade dos tubérculos-sementes.

Para produção de semente própria, muitos batateiros partem de minitubérculos, em geral, com alta qualidade fitossanitária. Porém, na multiplicação das sementes em campo, práticas importantes para manutenção da sanidade como, por exemplo, isolamento dos campos e erradicação de plantas doentes, não são observadas. Em conseqüência, produz-se tubérculo-semente com alta incidência de vírus, especialmente PVY (Tabela 1).

Considerações finais - No presente, a situação epidemiológica do PVY em batata é bastante complexa em todo o mundo, tendo sido discutida em detalhes por Singh et al. (2008). Esses autores propõem que os isolados continuem a ser descritos no nível de estirpes através da reação diferencial em cultivares de batata e fumo. Concomitantemente, a caracterização de seqüências de todo o genoma deve ser realizada.

Frente aos resultados deste levantamento, fica claro que PVY é hoje o principal vírus de batata no Brasil, com ampla disseminação do subgrupo necrótico, independente da região produtora ou da cultivar. Entretanto, PLRV, que era considerado sob controle, e PVS, que tinha uma ocorrência restrita, começam também a aparecer em incidência preocupante, o que pode ser conseqüência do abandono das práticas recomendadas para produção de tubérculos-semente.

Não se produz tubérculo-semente de alta qualidade fitossanitária sem uma certificação efetiva, que garanta a aplicação das boas práticas previstas na legislação.

\section{AGRADECIMENTOS}

Os autores agradecem ao $\mathrm{CNPq}$, ABASMIG (José Daniel R. Ribeiro), ABBA (Natalino Shimoyama), Associação do Irrigantes do Alto Paraguaçú (Kiyoshi Ishida), Castrolanda (Cleudiney Aparecido Iank), EMATER-PR (Paulo Roberto Fiorillo, Hamilton Borges), Embrapa Transferência de Tecnologia - Escritório de Negócios de Canoinhas (Odone Bertoncini, Gregório Heuko, Élcio Hirano), EMCAPER (Élcio Costa), Grupo Nascente (Edson M. Asano), IAPAR (Nilceu RX Nazareno), Montesa Agropecuária (Marcelo $\mathrm{B}$ de Carvalho, Felipe C Vieira) e Nagano Kinzi (Hélio Fabri Júnior.).

Nosso especial agradecimento a todos os produtores, da Bahia à Santa Catarina, que gentilmente cederam seus campos para amostragem.

\section{REFERÊNCIAS}

ANDREATTA A. 2006. Uma perspectiva do que ocorreu no setor nos últimos dez anos. Batata Show 16: 25-27.

ÁVILA AC; MELO PE; LEITE LR. 2007. O vírus Y da Batata (Potato virus Y) e a BatataSemente Nacional: Quem vencerá? Batata Show 17: 14-17.
BECZNER L; ROMHANYI I; FORSTER H. 1984. Studies on etiology of tuber necrotic ringspot disease in potato. Potato Research 27: 339-352.

CÂMARA FLA; CUPERTINO FP; FILGUEIRA FAR. 1986. Incidência de vírus em cultivares de batata multiplicadas sucessivamente em Goiás. Fitopatologia Brasileira 11: 711-716.

CLARK MF; ADAMS AN. 1977. Characteristics of the microplate method of enzyme linked immunosorbent assay for the detection of plant viruses. Journal of General Virology 34: 475-483.

CROSSLIN JM; HAMM PB; HANE DC; JAEGER J; BROWN CR; SHIEL PJ; BERGER PH; THORNTON RE. 2006. The Occurrence of PVY $Y^{\circ}, \mathrm{PVY}^{\mathrm{N}}$, and PVY ${ }^{\mathrm{N}: \mathrm{O}}$ Strains of Potato virus $\mathrm{Y}$ in Certified Potato Seed Lot Trials in Washington and Oregon. Plant Disease 1102-1105.

DANIELS J. 1995. Viroses da batata e suas implicações na produção de batata-semente no Rio Grande do Sul. Summa Phytopathologica: 269-270.

DANIELS J; PEREIRAAS. 2004. Resistência de genótipos de batata ao vírus do enrolamento da folha da batata (PLRV) e ao vírus Y (PVY). Horticultura Brasileira 22: 521-524.

FAO. Food and Agriculture Organization of the United Nations. 2009, 20 de maio. Disponível em: http://faostat.fao.org/site/567/ DesktopDefault.aspx?PageID=567\#ancor

FIGUEIRA AR. 1995. Viroses da batata e suas implicações na produção de batata-semente no estado de Minas Gerais: histórico do problema e soluções. Summa Phytopathologica 268269.

FIGUEIRA AR. 2006. Credenciamento do CIVMG no Renasem abre novas perspectivas para a melhoria da qualidade da batata-semente produzida no Brasil. Batata Show 16: 28.

FILGUEIRA FAR; CÂMARA FLA. 1986. Comportamento de cultivares européias de batata em gerações sucessivas. Horticultura Brasileira 4: 29-31.

FONSECA LN. 2003. Estudo da diversidade de Potato virus Y (PVY) em batata (Solanum tuberosum L.), no Brasil. Brasília: UCB. 73p (Tese mestrado).

FONSECA LN; INOUE-NAGATA AK; NAGATA T; SINGH RP; ÁVILA AC. 2005. Diferenciação de estirpes de Potato virus $Y$ (PVY) por RT-PCR. Horticultura Brasileira 23: 904-910

FONTES EG; MELO PE. 1999. Avaliação de riscos na introdução no ambiente de plantas transgênicas. In: TORRES AC; CALDAS LS; BUSO JA (eds). Cultura de tecidos e transformação genética de plantas. Brasília: Embrapa Comunicação Tecnológica. p. 815-843.

IBGE. Instituto Brasileiro de Geografia e Estatística. 2009, 18 de maio. Levantamento sistemático da Produção Agrícola. Disponível em: http://www.ibge.gov.br/home/estatistica/ indicadores/agropecuaria/lspa

INOUE-NAGATAAK; FONSECA MEN; LOBO TOTA; ÁVILA AC; MONTE DC. 2001. Análise da seqüência de nucleotídeos da capa protéica e da região $3^{\prime}$ não codificadora de 
dois isolados brasileiros de Potato virus $Y$. Fitopatologia Brasileira 26: 45-52.

KERLAN C; Le ROMANCER M. 1992. Potato tuber necrotic ringspot disease. In: EUROPEAN ASSOCIATION FOR POTATO RESEARCH MEETING, Virology Section. Proceedings... Victoria-Gasteiz: EAPR. p. 77-79.

KUS M. 1995. The epidemic of the tuber necrotic ringspot strain of Potato virus $Y$ (PVY $\left.{ }^{\mathrm{NTN}}\right)$ and its effect on potato crops in Slovenia. In: EUROPEAN ASSOCIATION FOR POTATO RESEARCH MEETING, Virology Section. 9. Proceedings...Bled: EAPR. p.159-160.

Le ROMANCER M; KERLAN C; NEDELLEC M. 1994. Biological characterisation of various geographical isolates of potato virus $Y$ inducing superficial necrosis on potato tubers. Plant Pathology 43: 138-144.

LEGNARO A; SÁBIO RP. 2007. Batata 2007: resultados positivos a partir de março. Hortifruti Brasil 64: 12-15.

NIE X; SINGH RP; SINGH M. 2004. Molecular and pathological characterization of $\mathrm{N}: \mathrm{O}$ isolates of the Potato virus Y from Manitoba, Canada. Canadian Journal of Plant. Phathology 26: 573-583.

NIVAP. The Netherlands Potato Consultative Foundation. 2007. The Netherlands catalogue of potato varieties. NIVAP: The Hague. $287 \mathrm{p}$.

OSHIMAK; SATOK; HIRAISHIC; NAKAGAWA A; MATSUO K; OGAWA T; SHIKATA E; SAKO N. 2000. Potato tuber necrotic ringspot disease occurring in Japan: its association with potato virus Y necrotic strain. Plant Disease 84: 1109-1115.

PICHE LM; SINGH RP; NIE X; GUDMESTAD NC. 2004. Diversity among Potato virus $Y$ isolates obtained from potatoes grown in the United States. Phytopathology 94: 13681375.

SALAZAR, LF. 1996. Potato viruses and their control. Peru: CIP. 214p.

SILVA PP. 2008. Caracterização biológica e molecular do complexo Potato virus Y (PVY) infectando plantas de batata de distintas regiões produtoras do Brasil. Brasília: UnB. 161p. (Tese mestrado).

SINGH RP; VALKONEN JPT; GRAY SM; BOONHAM N; JONES RAC; KERLAN C; SCHUBERT J. 2008. Discussion paper: the naming of Potato Virus $Y$ strains infecting potato. Archives of Virology 153: 1-13.

SOUZA-DIAS JAC. 1995. Viroses da batata e suas implicações na produção de batata-semente no estado de São Paulo. Summa Phytopathologica 21: 264-266.
SOUZA-DIAS JAC. 1996. Doença de causadas por vírus em batata. Informe. Agropecuário 184: 54-63.

SOUZA-DIAS JAC. 2001. Raças de vírus Y da batata (PVY) e a questão da variante NTN. Batata Show 2: 16-21.

SOUZA-DIAS JAC. 2006. Novo desafio: evidências apontam para a presença de uma estirpe exótica do PVY em lavouras de batata Monalisa na região de Casa Branca, São Paulo. Cultivar 6: 12-16.

STEINBACH P; HAMANN U. 1989. Symptome und Ursache einer wenig bekannten Ringnekrose der Kartoffelknolle. Archives Phytopatholol Pflanzenschutz 25: 223-232.

STEVENSON R; LORIA R. FRANC GD; WEINGARTNER DP. 2001. Compendium of Potato Diseases. St. Paul: The American Phytopathological Society. 134p.

van den HEUVEL JFJM; van der VLUGT RAA; VERBEEK M; de HAAN PT; HUNTTIGA H. 1994. Characteristics of a resistance-breaking isolate of Potato virus Y. European Journal of Plant Pathology 100: 347-356.

WEILGUNY H; SINGH RP. 1998. Separation of Slovenian isolates of PVY ${ }^{\mathrm{NTN}}$ from the North American isolates of $\mathrm{PVY}^{\mathrm{N}}$ by a 3-Primer PCR. Journal of Virological Methods 71: 57-68. 